\title{
Sibship (21q21q) Translocation Down's Syndrome with Maternal Transmission
}

\author{
M. FURBETTA, A. FALORNI, P. ANTIGNANI, and A. CAO \\ Paediatric Clinic and the Institute of Medical Furisprudence and Insurance, University of Perugia, Italy \\ Summary. A family is reported with eight cases of Down's syndrome and four \\ abortions in a sibship. The cytogenetic studies showed that the mother was a \\ (21q21q) translocation carrier. Two living children were examined and were found \\ to be cases of Down's syndrome with a (21q21q) translocation.
}

Familial Down's syndrome is a relatively rare finding (Hamerton, 1971) and may be due to an inherited translocation or other structural change, to gonadal mosaicism (normal/21 trisomy) in one parent, to parental predisposition to meiotic nondisjunction, or to a chance occurrence.

The structural changes which most commonly result in Down's syndrome are Robertsonian translocations, ie, $t(\mathrm{DqGq})$ and $t(\mathrm{GqGq})$.

In families with more than one affected sib (sibship Down's syndrome) an incidence of $25.6 \%$ of a segregating translocation was found while in families where more distant relatives were affected (kinship Down's syndrome) the incidence was $12.5 \%$ (Hamerton, 1971).

There is a $50 \%$ inheritance in $(\mathrm{DqGq})$ translocation Down's syndrome in contrast with the $(\mathrm{GqGq})$ type translocation which is inherited in only $6 \%$ of cases (Hamerton, 1971). (GqGq) translocation can be of three types, ie, (21q22q), (21q21q), or the long-arm isochromosome of number 21 (21qi). The last two types of rearrangements usually arise sporadically. A few families, however, have been described with a presumptive $t(21 \mathrm{q} 21 \mathrm{q})$ or $21 \mathrm{qi}$ balanced carrier (Fraccaro, Kaijser, and Lindsten, 1960; Hamerton et al, 1961; Forssman and Lehmann, 1962; Mukherjee, Miller, and Breg, 1962; Dallaire and Fraser, 1964; de Capoa et al, 1967/1968).

The present paper describes a family in which eight Down's syndrome children were found in a sibship. The pattern of inheritance and the identification of each chromosome pair with the ASG technique showed a familial (21q21q) translocation Down's syndrome with maternal transmission.

Received 2 July 1973.

\section{Family History}

This family was studied because the proposita, a female with Down's syndrome, aged 41 days, had seven sibs with the same syndrome. The pedigree is given in Fig. 1 and the clinical findings of the cases of Down's syndrome examined by one of us are presented in Table I.

The proposita (III.26) was first seen at the Paediatric Clinic at $\mathbf{4 1}$ days because of a respiratory distress syndrome. She was the result of the 12th pregnancy of a phenotypically normal mother (II.10) aged 41 at the time of her birth. The father (II.11) was aged 42 and also phenotypically normal. There is no history of consanguinity. Physical examination in the newborn period and at 6 months of age revealed a child with typical Down's syndrome (see Table I). Birth weight was $3200 \mathrm{~g}$, head circumference $32 \mathrm{~cm}$, and length $47 \mathrm{~cm}$. Death from progressive congestive heart failure occurred at the age of 30 months.

The first pregnancy of II.10 resulted in a boy (III.15), who was small for gestational age $(2500 \mathrm{~g})$ and died at home when 3 days old. The family doctor stated that the child was a case of Down's syndrome.

The second pregnancy resulted in a male child (III.16) who died at the age of 3 months in another hospital. The record states that the baby was a case of Down's syndrome and had a congenital heart malformation.

The third, fourth, and fifth pregnancies (III.17, III.18, III.19) were spontaneous abortions at two, three, and two months, respectively.

The sixth pregnancy resulted in a female child with Down's syndrome (III.20) with a congenital heart malformation. She died in our Clinic at the age of 6 months from congestive heart failure.

The seventh pregnancy resulted in a male child with Down's syndrome (III.21) who died when 2 days old from progressive cardiopulmonary failure. Necropsy examination revealed hypoplastic kidneys, a high ventricular septal defect, and a Meckel's diverticulum.

The eighth pregnancy (III.22) resulted in a female child who died 12 hours after birth from cardiopul- 


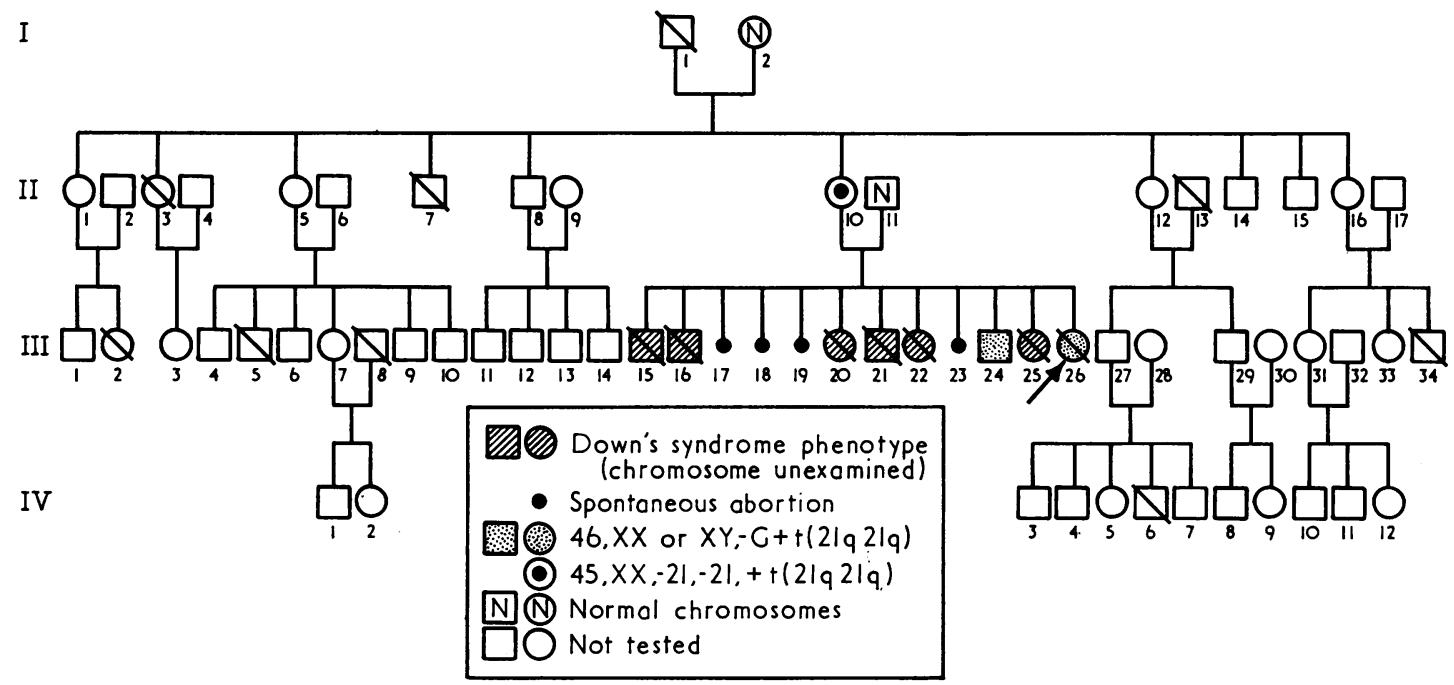

FIG. 1. Pedigree of the family.

monary failure. The record of the Obstetrics Department stated that the baby was affected by Down's syndrome.

The ninth pregnancy (III.23) was a spontaneous miscarriage at two months.

The 10th offspring (III.24) is a male child with Down's syndrome aged 5 years and the 11th offspring (III.25) was a female child with Down's syndrome who died when 8 months old from progressive cardiopulmonary failure.

There were no other relevant data in the family history and in particular there was no history of mental retardation or congenital malformation.

\section{Chromosome Studies}

The chromosomes of the proposita (III.26), her sib (III.24), and her parents were studied from blood cultures using the method of Moorhead et al (1960). Fifty metaphases were counted and 10 karyotypes were prepared.

Chromosomal analysis of the proposita and her sib showed a modal count of 46 ; there was a missing G-group chromosome and an extra metacentric chromosome resembling members of the $F$ group (Fig. 2). The karyotypes were interpreted as $46, \mathrm{XX}$ or $\mathrm{XY},-\mathrm{G},+\mathrm{t}(\mathrm{GqGq})$. Chromosomal studies of the mother revealed a modal count of 45 ; group G was composed of only two members and an extra F-like metacentric was present (Fig. 2). The karyotype was interpreted as $45, \mathrm{XX},+\mathrm{t}(\mathrm{GqGq})$. The analysis of chromosomes was performed also with the ASG technique (Sumner, Evans, and Buckland, 1971). There were two unaltered num- bers 22 , the missing $G$ members were therefore interpreted as chromosomes 21 and the extra chromosomes as (21q21q) translocation chromosomes (Fig. 3).

\section{Discussion}

In the family described the ASG technique showed the mother to be a carrier of a (21q21q) translocation chromosome. A (21q21q) translocation carrier can arise from a postfertilization mitotic error of a normal zygote (Hamerton, 1971). A more remote hypothesis implies the simultaneous occurrence of two independent and abnormal events, translocation in one parent and non-disjunction in the other (Dallaire and Fraser, 1964). A balanced 21qi heterozygote cannot be ruled out by the ASG technique. It should be underlined, however, that the origin of a balanced 21qi carrier is more difficult to explain and that the subjects described with a presumptive 21qi were mixoploids (Fraccaro et al, 1960; Hamerton et al, 1961).

According to the segregation pattern of a (21q21q) translocation carrier the pregnancies resulted in eight cases of Down's syndrome and four abortions. In the (21q21q) translocation carrier only two types of gametes are formed: either with the abnormal chromosome containing the double genetic material of a 21 chromosome or without 21 chromosome. After fertilization the zygote will be abnormal: either trisomic or monosomic for a 21 chromosome.

With the exception of some rare cases (Gripenberg, Elfving, and Gripenberg, 1972) G monosomy 


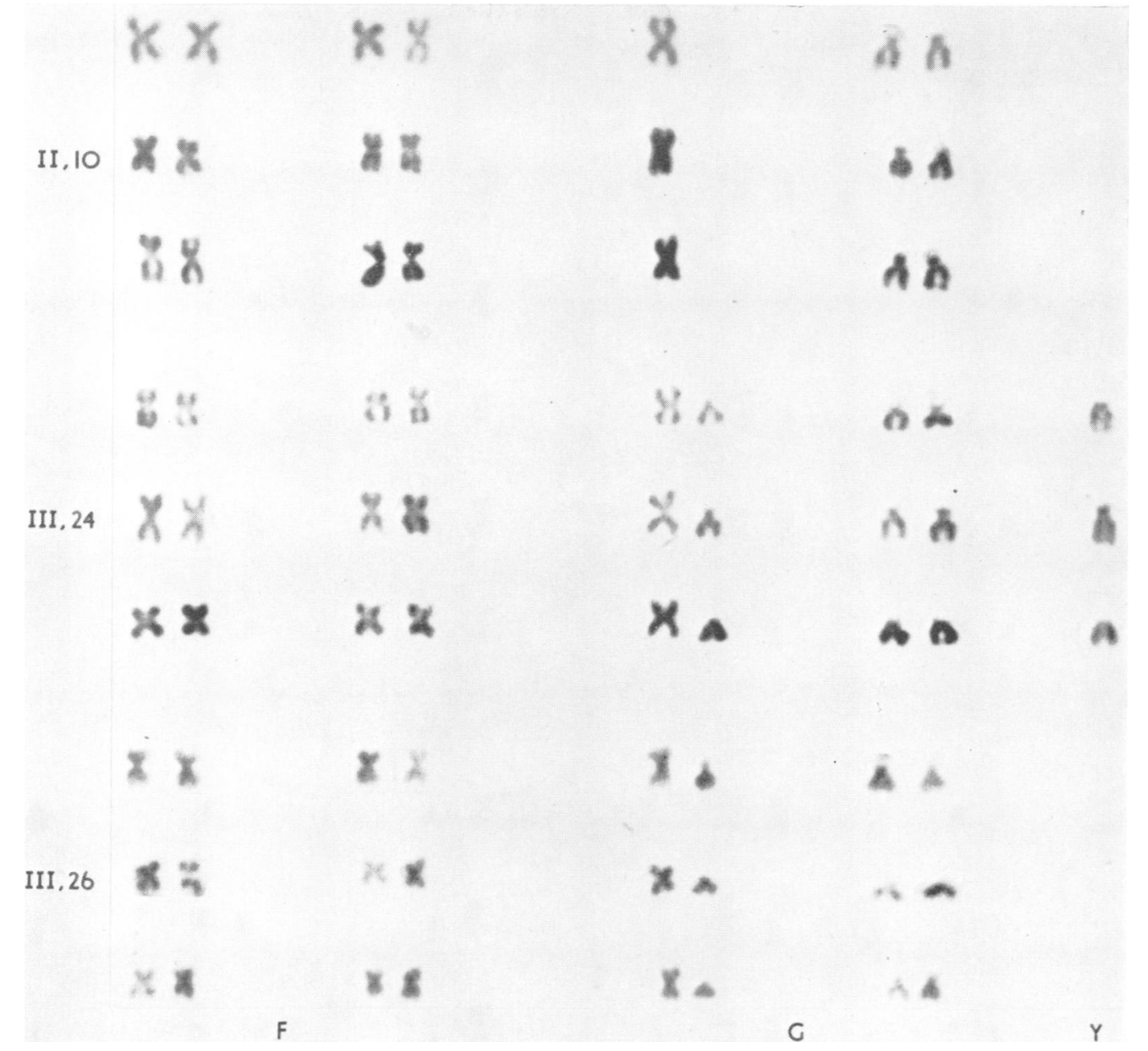

FIG. 2. Partial karyotypes from peripheral blood lymphocyte metaphases of the proposita (III.26), her sib (III.24), and the mother (II.10).

seems generally non-viable. Therefore all the offspring of a carrier are affected and the risk of a carrier parent having a child with Down's syndrome is $100 \%$.

Hamerton et al (1961) reported a sibship with two cases of Down's syndrome and one abortion. The patients had 46 chromosomes and a ( $\mathrm{GqGq})$ translocation; the mother was a $(\mathrm{GqGq})$ translocation carrier. A similar sibship with five boys with Down's syndrome and one abortion was reported by Dallaire and Fraser (1964). The father was found to have 45 chromosomes and a $(\mathrm{GqGq})$ translocation and four sibs with Down's syndrome examined had 46 chromosomes and a (GqGq) translocation.
Forssman and Lehmann (1962) reported a family with two or probably three offspring with Down's syndrome and five miscarriages in a sibship. The father was a phenotypically normal (GqGq) translocation carrier and the offspring with Down's syndrome who was examined had 46 chromosomes and $a(\mathrm{GqGq})$ translocation.

In the family reported by Mukherjee et al (1962) the mother was a $(\mathrm{GqGq})$ translocation carrier. The pregnancies resulted in three offspring with Down's syndrome. One child with Down's syndrome had a (GqGq) translocation.

De Capoa et al (1967/1968) described a family where the mother was a (GqGq) translocation carrier. 


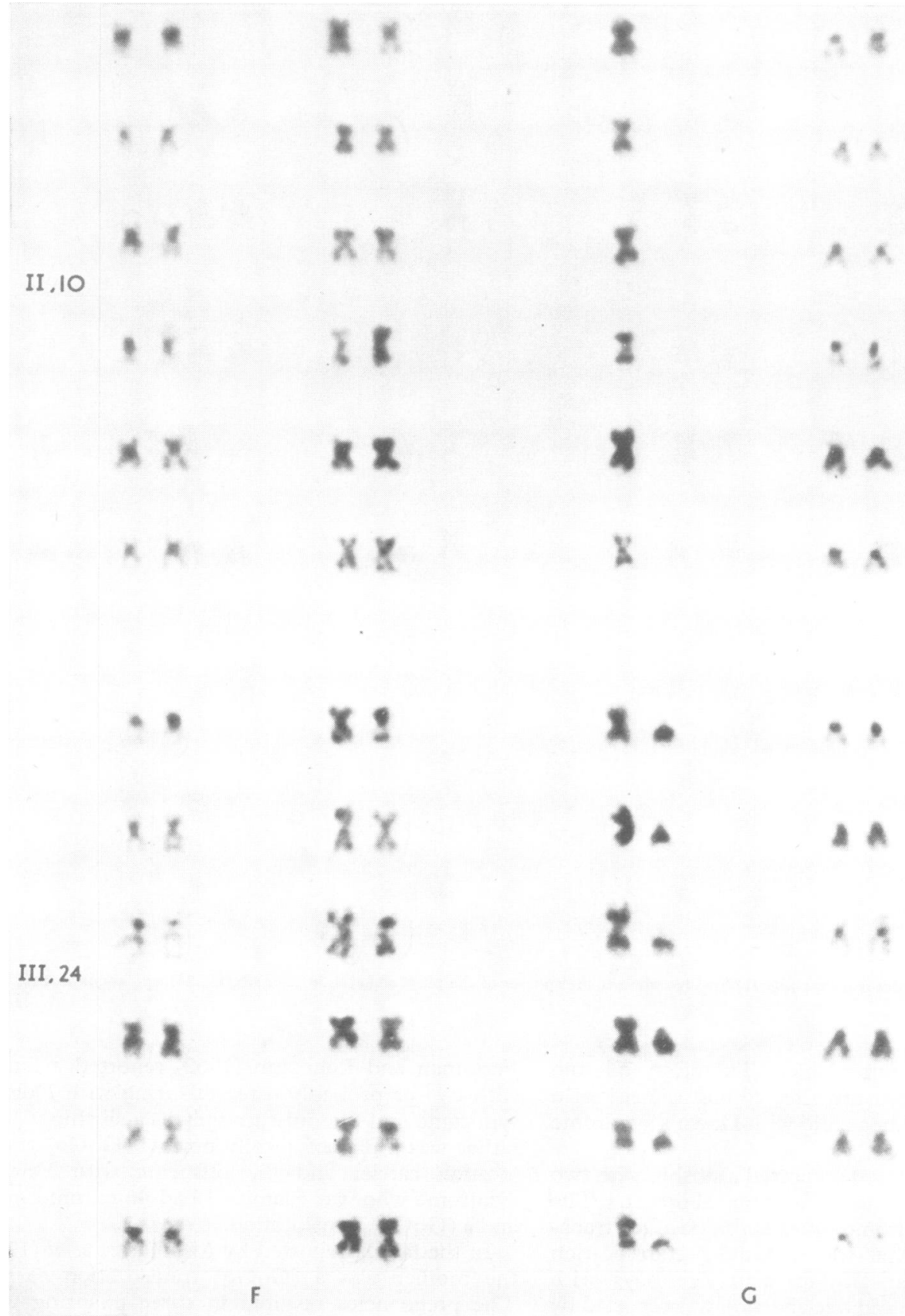

FIG. 3. Partial karyotypes from peripheral blood lymphocyte metaphases of Giemsa-banded cells of the mother (II.10) and the sib (III.24) of the proposita. 
TABLE I

CLINICAL FINDINGS OF CASES OF DOWN'S SYNDROME

\begin{tabular}{|c|c|c|c|c|}
\hline & \multicolumn{4}{|c|}{ Case } \\
\hline & III. 20 & III.21 & III. 24 & III. 25 \\
\hline Age at examination & 6 months & 2 days & 5 years & 8 months \\
\hline $\begin{array}{l}\text { Protruding tongue } \\
\text { Furrowed tongue } \\
\text { Oblique palpebral fissures } \\
\text { Epicanthic folds } \\
\text { Brushfield spots } \\
\text { Dysplastic ears } \\
\text { Abundant skin on the neck } \\
\text { Flat occiput } \\
\text { Flat facial profile } \\
\text { Short and broad hands } \\
\text { Curved fifth finger } \\
\text { Four-finger crease } \\
\text { Dysplastic middle phalanx fifth finger } \\
\text { Joint hypermobility } \\
\text { Muscular hypotonia } \\
\text { Lack of Moro reflex } \\
\text { Heart murmur } \\
\text { Slow mental and motor development }\end{array}$ & $\begin{array}{l}+ \\
+ \\
+ \\
+ \\
+ \\
+ \\
+ \\
+ \\
+ \\
+ \\
+ \\
+ \\
+ \\
+ \\
+ \\
+ \\
+ \\
+\end{array}$ & $\begin{array}{l}- \\
- \\
+ \\
- \\
- \\
+ \\
+ \\
+ \\
\pm \\
- \\
+ \\
+ \\
+ \\
+ \\
+ \\
+ \\
+ \\
+\end{array}$ & $\begin{array}{l}+ \\
+ \\
+ \\
+ \\
+ \\
+ \\
+ \\
+ \\
+ \\
+ \\
+ \\
+ \\
+ \\
+ \\
+ \\
+ \\
+\end{array}$ & $\begin{array}{l}+ \\
+ \\
+ \\
+ \\
+ \\
+ \\
+ \\
+ \\
+ \\
+ \\
+ \\
+ \\
+ \\
+ \\
+ \\
+ \\
+ \\
+\end{array}$ \\
\hline Remarks & & $\begin{array}{l}\text { Died at } 6 \mathrm{mth} \text { from congestive } \\
\text { heart failure. } \\
\text { Necropsy examination: } \\
\text { hypoplastic kidneys; } \\
\text { ventricular septal defect; } \\
\text { Meckel's diverticulum }\end{array}$ & & \\
\hline
\end{tabular}

She had four ( $\mathrm{GqGq}$ ) translocation offspring with Down's syndrome and an abortion with a 46,XX, - G, $+\mathrm{t}(\mathrm{GqGq})$ karyotype. Autoradiography demonstrated the translocation chromosome to be derived from the two later-labelling, G-group chromosomes.

Previously the identification of a (21q21q) translocation relied largely on knowledge of the family history.

Our study showed that the ASG technique is a useful means for identifying a $(\mathrm{GqGq})$ translocation chromosome as translocation type (21q22q) or (21q21q). This technique has improved the reliability of genetic counselling in Down's syndrome.

Similar results in the identification of a translocation chromosome were obtained by fluorescence analysis (Breg et al, 1971; Uchida and Lin, 1971). Caspersson et al (1971), however, recently found that quinacrine mustard fluorescence analysis did not always permit an identification of a Robertsonian translocation since the pattern of a $(21 \mathrm{q} 21 \mathrm{q})$ translocation cannot be differentiated from that of a normal chromosome 20.

\section{REFERENCES}

Breg, W. R., Miller, O. J., Miller, D. A. and Allderdice, P. W. (1971). Distinctive fluorescence of quinacrine-labelled human $G$ group chromosomes. Nature New Biology, 231, 276-277.

Capoa, A. de, Miller, O. J., Mukherjee, B. B., and Warburton, D.
(1967/1968). Autoradiographic studies on a mother and aborted foetus from a family with four mongoloid children and a presumptive 21/21 translocation. Annals of Human Genetics, 31, 243-253.

Caspersson, T., Hultén, M., Lindsten, J., Therkelsen, A. J., and Zech, L. (1971). Identification of different Robertsonian translocations in man by quinacrine mustard fluorescence analysis. Hereditas, Genetiskt Arkiv, 67, 213-220.

Dallaire, L. and Fraser, F. C. (1964). Two unusual cases of familial mongolism. Canadian fournal of Genetics and Cytology, 6, 540-547.

Forssman, H. and Lehmann, O. (1962). Chromosome studies in eleven families with mongolism in more than one member. Acta Paediatrica, 51, 180-188.

Fraccaro, M., Kaijser, K., and Lindsten, J. (1960). Chromosomal abnormalities in father and mongol child. Lancet, 1, 720-727.

Gripenberg, U., Elfving, J., and Gripenberg, L. (1972). A 45,XX,21- child: attempt at a cytological and clinical interpretation of the karyotype. Fournal of Medical Genetics, 9, 110-114.

Hamerton, J. L. (1971). Human Cytogenetics, vol. 2, pp. 236-238. Academic Press, New York.

Hamerton, J. L., Briggs, S. M., Giannelli, F., and Carter, C. O. (1961). Chromosome studies in detection of parents with high risk of second child with Down's syndrome. Lancet, 2, 788-791.

Moorhead, P. S., Nowell, P. C., Mellman, W. J., Battips, D. M., and Hungerford, D. A. (1960). Chromosome preparation of leukocytes, cultured from human peripheral blood. Experimental Cell Research, 20, 613-616.

Mukherjee, B. B., Miller, O. J., and Breg, W. R. (1962). Chromosome rearrangement (a 21/21 isochromosome (?)) as a cause of familial mongolism. Abstracts, American Society of Human Genetics, No. 558, p. 7.

Sumner, A. T., Evans, H. J., and Buckland, R. A. (1971). New technique for distinguishing between human chromosomes. Nature New Biology, 232, 31-32.

Uchida, I. A. and Lin, C. C. (1971). Fluorescent staining of human chromosomes: identification of some common aberrations. Canadian Medical Association fournal, 105, 479-482. 